\title{
Hydro-Pyrolysis and Catalytic Upgrading of Biomass and Its Hydroxy Residue Fast Pyrolysis Vapors
}

\author{
Yichen Liu ${ }^{1}$, James J. Leahy ${ }^{1,2}{ }^{\text {, Jacek Grams }}{ }^{3}$ (I) and Witold Kwapinski ${ }^{1,2, * \mathbb{C}}$ \\ 1 Carbolea Research Group, Department of Chemical Sciences, University of Limerick, \\ Limerick V94T9PX, Ireland \\ 2 Bernall Institute, University of Limerick, Limerick V94 T9PX, Ireland \\ 3 Institute of General and Ecological Chemistry, Faculty of Chemistry, Lodz University of Technology, \\ Zeromskiego 116, 90-924 Lodz, Poland \\ * Correspondence: witold.kwapinski@ul.ie; Tel.: +353(0)61234935
}

Received: 4 July 2019; Accepted: 30 August 2019; Published: 9 September 2019

\begin{abstract}
Fast pyrolysis of Miscanthus, its hydrolysis residue and lignin were carried with a pyrolysis-gas chromatography/mass spectrometry (Py-GC/MS) followed by online vapor catalytic upgrading with sulfated $\mathrm{ZrO}_{2}$, sulfated $\mathrm{TiO}_{2}$ and sulfated $60 \mathrm{wt} . \% \mathrm{ZrO}_{2}-\mathrm{TiO}_{2}$. The most evident influence of the catalyst on the vapor phase composition was observed for aromatic hydrocarbons, light phenols and heavy phenols. A larger amount of light phenols was detected, especially when 60 wt. $\% \mathrm{ZrO}_{2}-\mathrm{TiO}_{2}$ was present. Thus, a lower average molecular weight and lower viscosity of bio-oil could be obtained with this catalyst. Pyrolysis was also performed at different pressures of hydrogen. The pressure of $\mathrm{H}_{2}$ has a great effect on the overall yield and the composition of biomass vapors. The peak area percentages of both aromatic hydrocarbons and cyclo-alkanes are enhanced with the increasing of $\mathrm{H}_{2}$ pressure. The overall yields are higher with the addition of either $\mathrm{H}_{2}$ or sulfated catalysts. This is beneficial as phenols are valuable chemicals, thus, increasing the value of bio-oil. The results show that the hydrolysis residue has the potential to become a resource for phenol production.
\end{abstract}

Keywords: Py-GC/MS; $\mathrm{ZrO}_{2} ; \mathrm{TiO}_{2}$; biorefinery; acid hydrolysis; $\mathrm{HDO}$; hydropyrolysis; Miscanthus

\section{Introduction}

In recent years, the fast pyrolysis of lignocellulose for production so-called 2nd generation bio-fuels has attracted more attention. Pyrolysis is a process of thermal decomposition under high temperature without oxygen. Bio-oil, as the liquid product of lignocellulosic biomass fast pyrolysis, is considered to have the potential to replace fossil fuels for the production of biofuels and various chemical compounds [1]. Nevertheless, the bio-oil possesses many undesirable properties, which prohibit the application and production. The high content of carboxylic acids leads to the corrosiveness of bio-oil. A large amount of carbonyl group compounds, such as aldehydes and ketones are mainly responsible for the bio-oil thermal instability. The high oxygen content causes the bio-oil low heating value. As a result, the poor fuel quality of bio-oil makes it hard to be used directly, and its upgrading is necessary to be carried out.

There are several different approaches to upgrade crude bio-oil to better quality fuel. As a result, the upgrading process must remove oxygen and convert unwanted products to more beneficial species. One such upgrading processes are catalytic cracking, which can be conducted either offline (after pyrolysis, on liquid bio-oil) or online (during pyrolysis, on vapors products). There are possible disadvantages of upgrading bio-oil after pyrolysis, such as rapid catalyst deactivation due to coke formation on the catalyst surface and/or bio-oil aging during storage because of the presence of 
certain reactive compositions. The contact between the liquid phase and solid catalyst is less efficient than vapor phase, which allows reducing reaction time by faster mass transfer. As a result, catalytic cracking is considered as a method which can help to solve numerous problems connected to bio-oil upgrading [2-5].

The key to catalytic cracking is the application of a proper catalyst (Grams and Ruppert, 2017). Zeolites are most commonly studied, such as HZSM-5, SBA-15 and their modified counterparts. French and Czernik (2010) [6] studied 40 different catalysts and found the Ni/ZSM-5 catalyst favored the highest hydrocarbon yield. However, many drawbacks to using ZSM-5 were encountered: Rapid catalyst deactivation, due to coke formation on the catalyst surface, low efficiency of organic fractions and generation of polycyclic aromatic hydrocarbons. Moreover, $\gamma-\mathrm{Al}_{2} \mathrm{O}_{3}$ was previously used to hydrotreating oxygenated compounds, but large carbon deposition and high water sensitivity were observed [7]. $\mathrm{ZrO}_{2}$ has been found very effective in the process of cracking of large molecules present in pyrolysis vapors. That is why it can be applied to improve the properties of the vapor products of the mentioned process [8-10]. The application of mixed oxides titania and zirconia has attracted the attention of researchers [11-14], due to an interesting feature as it is the presence of both acidic and basic sites. Metal oxides-based catalyst are more feasible in different catalytic conditions because of their unique properties and better hydrothermal stability than zeolite catalysts [15].

Lignocellulosic biomass is a hydrogen deficient feedstock. Moreover, further hydrogen depletion may be observed during catalytic cracking of the formed vapors as the oxygen is usually removed in the form of water molecules. To conquer these disadvantages $\mathrm{H}_{2}$, is introduced during pyrolysis, and it can proceed by hydro-pyrolysis or hydro-deoxygenation (HDO) and has been studied extensively [16-18]. In contrast to catalytic cracking, the hydro-pyrolysis and HDO are typically carried out under very severe conditions, with pressures of up to $20 \mathrm{MPa}$. The most preferred used catalysts are a transition or noble metal catalysts. Although the mechanisms of transition and noble metal catalysts are not fully understood, it is generally believed that the metals act as the hydrogen donation site [19]. The combined mechanism is the adsorption and activation of the oxy-compound occur on the surface of the support, which has the potential to activate $\mathrm{H}_{2}$ [20].

Lignin is the second most abundant component of biomass, which can take up to $30 \mathrm{wt} . \%$ of lignocellulosic biomass. It is the most heat resistant bio-compound of biomass, and is decomposed in the temperature range of $280-500{ }^{\circ} \mathrm{C}$ [21]. Therefore, more residual char is expected to be produced from lignin pyrolysis than during the pyrolysis of cellulose or hemicellulose. Lignin was usually treated as hydrolysis residue or waste from the paper industry [22], and mainly used as a low-grade energy source in combustion [23]. However, the high content of lignin in lignocellulosic biomass and its chemical structure makes it a potential candidate to be used as valuable chemicals resource for compounds, such as phenolics.

In this study, pure sulfated $\left(\mathrm{SO}_{4}{ }^{2-}\right) / \mathrm{TiO}_{2}$, pure $\mathrm{SO}_{4}{ }^{2-} / \mathrm{ZrO}_{2}$ and 60 wt. $\% \mathrm{SO}_{4}{ }^{2-} / \mathrm{ZrO}_{2}-\mathrm{TiO}_{2}$ mix were selected for biomass fast pyrolysis vapors catalytic upgrading. Different $\mathrm{H}_{2}$ pressures were also introduced to investigate the $\mathrm{H}_{2}$ pressure effect on catalytic products. Miscanthus (M), lignin and hydrolysis residue (HR) were used as feedstock. All the experiments were performed with the use of Pyrolsis-GC/MS (Py-GC/MS) to allow the online catalytic upgrading of biomass fast pyrolysis vapors.

Miscanthus contains cellulose and hemicellulose, as well as lignin components, and was a feedstock in the hydrolysis process. It is a high yielding perennial energy crop. Its production ranged from 4-25 t/ha.pa. dry matter in the area of Central Europe, to 30-40 t/ha.pa. in Southern Europe can be observed. Interestingly, $\mathrm{M}$ can give the mentioned yields, even with the addition of limited amounts of herbicides or fertilizers [24]. The HR was a by-product from the acid hydrolysis of M conversion to platform chemicals: Furfural, levulinic acid and formic acid [25]. The left-over HR can take up to $50 \mathrm{wt} . \%$ of the original biomass. The residue is mostly made up of lignin, which is resistant to hydrolysis, and transformed by the polymerization of reaction intermediates. The pyrolysis of the residue leads to the formation of mainly char and gases. $M$ and lignin were used for comparison 
purposes for HR conversion. Their presence as two analogues will allow for the unique products of the HR conversions to be determined, and allows for estimation of possible routes of products formation.

\section{Experiments}

\subsection{Catalyst Preparation}

Every catalyst was synthesized by a deposition precipitation method. At the beginning of the preparation procedure, stoichiometric quantities of $\mathrm{ZrOCl}_{2}$ (purity $\geq 99.5 \%$, Sigma-Aldrich) and $\mathrm{TiO}_{2}$ (anatase, Sigma-Aldrich) (about $100 \mathrm{mg}$ ) were mixed in distilled $\mathrm{H}_{2} \mathrm{O}$. Then, aqueous $\mathrm{NH}_{3}$ solution was added dropwise to the slurry which was subjected to constant stirring in order to adjust $\mathrm{pH}$ to 10 . The obtained precipitate was filtered and then dried after aging for $24 \mathrm{~h}$, followed by dipping in $\mathrm{H}_{2} \mathrm{SO}_{4}$ $(1 \mathrm{~mol} / \mathrm{L})$ for $4 \mathrm{~h}$. The white solid substance that was formed was then dried in an oven, overnight, at $80^{\circ} \mathrm{C}$. Afterwards, it was calcined in a furnace for $5 \mathrm{~h}$ at $500{ }^{\circ} \mathrm{C}$. Pure $\mathrm{SO}_{4}{ }^{2-} / \mathrm{ZrO}_{2}$ was prepared by the same method without $\mathrm{TiO}_{2}$ mixed in the beginning. Pure $\mathrm{SO}_{4}{ }^{2-} / \mathrm{TiO}_{2}$ was made from the step dipping in $\mathrm{H}_{2} \mathrm{SO}_{4}$ and the same way as the rest of the catalysts.

\subsection{Catalyst Characterization}

X-ray diffraction (XRD) analysis was performed with the use of $\mathrm{CuK} \alpha$ radiation in a Philip X'Pert diffactometer. The experiments were carried out in order to determine the crystal structure of the investigated catalysts and establish the presence of different crystallographic phases in the studied samples. The scanning speed applied during measurements was 0.025 degree $/ \mathrm{min}$, and the range of 2-theta angle was between $5^{\circ}$ to $80^{\circ}$.

Infrared spectroscopy (IR) measurements were carried out with the use of a Bomem spectrometer in the range from 4000 to $400 \mathrm{~cm}^{-1}$.

The surface area was determined with the use of Micromeritics Gemini surface analyzer. The obtained results were calculated using Brunauer Emmett Teller (BET) equation.

The content of acid sites present on the surface of the catalysts was determined by exchange in sodium chloride solution followed by titration with sodium hydroxide solution. In the performed experiments, $0.4 \mathrm{~g}$ of the investigated catalyst was added to $100 \mathrm{~cm}^{3}$ of aqueous solution of sodium chloride $\left(0.1 \mathrm{~mol} / \mathrm{dm}^{3}\right)$. Then, the obtained mixture was stirred until equilibrated for $24 \mathrm{~h}$. The white suspension that was formed was then, in the following step, titrated by the addition of sodium hydroxide solution $\left(0.009 \mathrm{~mol} / \mathrm{dm}^{3}\right)$.

\subsection{Pyrolysis-Gas Chromatography/Mass Spectrometry Technique}

Py-GC/MS is a combined approach of chemical analysis in which the samples are heated to decomposition to generate smaller molecules, then be separated by GC and detected by MS. The detection range of GC-MS is limited and usually it is possible to determine ions with mass up to $800 \mathrm{amu}$. In a typical run of Py-GC/MS, the pyrolysis was performed with the use of CDS Analytical 5200 pyroprobe, which is composed of two parts. The first part is for pyrolysis; biomass will be heated in the presence of helium, which acts as the carrier gas. The second part is catalyst reactor, where the cracking occurs. In a typical reaction, $1.5 \mathrm{mg}( \pm 0.01 \mathrm{mg})$ of miscanthus was inserted in a quartz tube, protected on both sides by quartz wool. Because of the precise weight preparation process, the changes in the area of corresponding peaks of all analyzed compounds can be considered indicators of general content variations in the samples. $5 \mathrm{mg}( \pm 0.01 \mathrm{mg})$ of the catalyst was placed in the catalyst reactor. The heating rate of the feedstock was $20^{\circ} \mathrm{C} / \mathrm{ms}$. The samples of miscanthus were held at $600{ }^{\circ} \mathrm{C}$ for $20 \mathrm{~s}$. The vapor products were passed through the reactor with the catalyst bed heated to $300^{\circ} \mathrm{C}$ after the pyrolysis. Then they were trapped on an adsorption column (Tenax), which was held at $30^{\circ} \mathrm{C}$. Afterwards, the trapper was rapidly heated to $280^{\circ} \mathrm{C}$, which would desorb all compounds which were in the molecular weight range of 40 to $310 \mathrm{~g} / \mathrm{mol}$. All the vapors were then passed through GC (Agilent GC 7890A, Santa Clara, CA, USA) and separated by HP-5MS capillary column $(30 \mathrm{~m} \times 0.25 \mathrm{~mm}$, 
$0.25 \mu \mathrm{m}$ film thickness), to then be analyzed by MS (Agilent MS 5975C, Santa Clara, CA, USA). He (high purity) was used as carrier gas (its flow rate was $4 \mathrm{ml} / \mathrm{min}$ ). The spilt mode 1: 50 was applied during the analysis. The temperature of the column increased from $30^{\circ} \mathrm{C}$ (held for $10 \mathrm{~min}$ ) to $280^{\circ} \mathrm{C}$ (held for $10 \mathrm{~min}$ ) with a heating rate of $5^{\circ} \mathrm{C} / \mathrm{min}$. The mass analyzer allowed for the identification of ions with $\mathrm{m} / \mathrm{z}$ from 40 to 400 . The chromatographic peaks were ascribed to particular compounds according to the NIST MS library. Due to feedstock inhomogeneity and small capacity that can be used during the experiments in pyro-probe reproducibility can be a problem. However, by completing this experiment carefully, we were able to repeat them no more than five times to achieve a relative standard deviation within $10 \%$ for GC/MS peak area percentage between each sample of pyrolysis vapors.

\subsection{Feedstock Properties}

Elemental compositions $(\mathrm{C}, \mathrm{H}, \mathrm{N}, \mathrm{S})$ were tested by using elemental analysis (Elemental Vario el Cube analyzer). Sulphanilaide was used as a standard. The analysis result is based on the comparison between experimental data and theoretical calculation of sulphanilaid elemental content.

The analysis of moisture present in investigated biomass samples was performed in a crucible of known weight. The samples (mass between 0.2 and $0.5 \mathrm{~g}$ ) were dried in an oven overnight at $105^{\circ} \mathrm{C}$. The measurements were usually carried out in duplicate.

The measurements of ash content in the analyzed biomass materials were performed according to ICS 75.160.10, DD CEN/TS 14775:2004.

Preparation of raw biomass and torrefied samples for the analysis of chemical composition was carried out in accordance with following standards: "E1757-01 (preparation for compositional analysis), D 1150-96 (preparation of extractive free biomass) and D 1107-96 (ethanol-toluene solubility of biomass)". The amount of cellulose, hemicellulose and lignin was identified by hydrolyzing the biomass ( $300 \mathrm{mg}$ ) with $3.00 \mathrm{~mL}$ of $\mathrm{H}_{2} \mathrm{SO}_{4}$ (conc. $72 \%$ ) and mixing thoroughly-a detail description can be found in Xue et al. (2014) [26]. The formed hydrolysate was utilized for the identification of carbohydrates fraction and acid soluble lignin (ASL). Their contents were determined by HPLC with the use of ICS-3000 ion chromatography system, (Dionex), equipped with a CarboPac PA1, $4 \times 250 \mathrm{~mm}$ (Dionex) column and pulsed amperometric (PAD) and diode array detectors (Agilent HP 8452A). The solid residue corresponds to the Acid-Insoluble Residue, while its free-ash fraction is connected with the Klason Lignin. The analysis was conducted in duplicate. The contribution of cellulose was determined by the amount of glucan. On the other hand, other carbohydrates (i.e. xylan and arabinan) were counted as hemi-cellulose.

The FOSS XDS monochromator, with the associated rapid content analyzer (RCA) module and its solids transport attachment, are used for the near infrared analysis of biomass samples (extractives content for biomass).

The higher heating value (HHV) of biomass samples were measured by an oxygen bomb calorimeter (442 m Parr Company, Moline, IL, USA). The standard for the instrument calibration was benzoic acid.

Table 1 shows the properties of the M, HR and lignin. The lignin content in HR is much higher than that in $\mathrm{M}$, and no sugar is detected. As a result, $\mathrm{HR}$ has the potential to become a resource for phenolics production.

Table 1. The composition of Miscanthus (M), hydrolysis residue (HR) and lignin. * calculated by difference.

\begin{tabular}{cccc}
\hline Properties & M & HR & Lignin \\
\hline Moisture, wt. $\%$ & $8.82 \pm 0.22$ & $6.21 \pm 0.20$ & - \\
Cellulose, wt.\% & $37.1 \pm 2.2$ & 0 & - \\
Hemicellulose, wt.\% & $18.0 \pm 1.2$ & 0 & - \\
Lignin, wt.\% & $20.1 \pm 3.4$ & $44.2 \pm 4.4$ & 100 \\
Ash, wt.\% & $3.55 \pm 0.42$ & $18.1 \pm 1.31$ & - \\
\hline
\end{tabular}


Table 1. Cont.

\begin{tabular}{cccc}
\hline Properties & M & HR & Lignin \\
\hline C, wt.\% & 46.6 & 55.7 & 54.1 \\
H, wt.\% & 6.36 & 4.75 & 5.39 \\
N, wt.\% & 0.41 & 0.37 & 0.62 \\
S, wt.\% & - & - & 4 \\
O * wt. $\%$ & 46.6 & 39.2 & 35.9 \\
HHV, kJ/g & 18.7 & 20.2 & 22.3 \\
\hline
\end{tabular}

\section{Results and Discussion}

\subsection{Characterization of Catalysts}

The catalyst surface area and surface acidity are shown in Table 2 (measurements presented in Table 2 have not been multiplied). The surface of pure $\mathrm{TiO}_{2}$ is low compared to pure $\mathrm{ZrO}_{2}$. The introduction of zirconia to titania causes growth in surface area of the catalyst. That is why it is able to accept more $\mathrm{SO}_{4}{ }^{2-}$ as active sites. Owing to that, an increase in the average surface acidity per square meter can be observed. Based on an earlier study [14], the $60 \mathrm{wt} . \% \mathrm{ZrO}_{2}-\mathrm{TiO}_{2}$ had one of the highest catalytic activities among the catalysts with different $\mathrm{ZrO}_{2}: \mathrm{TiO}_{2}$ ratio and was chosen as the optimal oxide mixture.

Table 2. Selected surface properties of studied catalysts.

\begin{tabular}{cccccc}
\hline Catalysts & $\begin{array}{c}\text { Surface Area } \\
\mathbf{m}^{2} / \mathbf{g}\end{array}$ & $\begin{array}{c}\text { Surface } \\
\text { Acidity } \boldsymbol{\mu \mathbf { m o l } / \mathbf { g }}\end{array}$ & $\begin{array}{c}\text { Surface Acidity } \\
\boldsymbol{\mu m o l} / \mathbf{m}^{\mathbf{2}}\end{array}$ & $\begin{array}{c}\text { Pore Volume } \\
\mathbf{c m}^{\mathbf{3}} / \mathbf{g}\end{array}$ & $\begin{array}{c}\text { Pore Diameter } \\
\mathbf{n m}\end{array}$ \\
\hline pure $\mathrm{TiO}_{2}$ & 14.4 & 58.2 & 4.04 & 0.112 & 8.3 \\
60 wt. $\% \mathrm{ZrO}_{2}-\mathrm{TiO}_{2}$ & 103 & 493 & 4.81 & 0.262 & 4.9 \\
pure $\mathrm{ZrO}_{2}$ & 97.3 & 469 & 4.82 & 0.255 & 6.2 \\
\hline
\end{tabular}

The results of XRD analysis are presented in Figure 1. The signals at $25.5^{\circ}, 37.1^{\circ}, 38.7^{\circ}, 39.9^{\circ}$, $48.3^{\circ}, 54.0^{\circ}, 55.3^{\circ}$ correspond to the diffraction of anatase $\mathrm{TiO}_{2}$, which appear in pure $\mathrm{TiO}_{2}$ and $60 \mathrm{wt} . \%$ $\mathrm{ZrO}_{2}-\mathrm{TiO}_{2}$ samples. The peaks at $28.6^{\circ}, 30.7^{\circ}, 31.8^{\circ}, 51.0^{\circ}$ and $59.9^{\circ}$ are ascribed to zirconia [27]. They can be observed for the $60 \mathrm{wt} . \% \mathrm{ZrO}_{2}-\mathrm{TiO}_{2}$ and pure $\mathrm{ZrO}_{2}$ catalysts. The formation of $\mathrm{ZrTiO}_{4}$ was not confirmed by the XRD analysis, because it can be created when the temperature is higher than $500{ }^{\circ} \mathrm{C}[28]$.

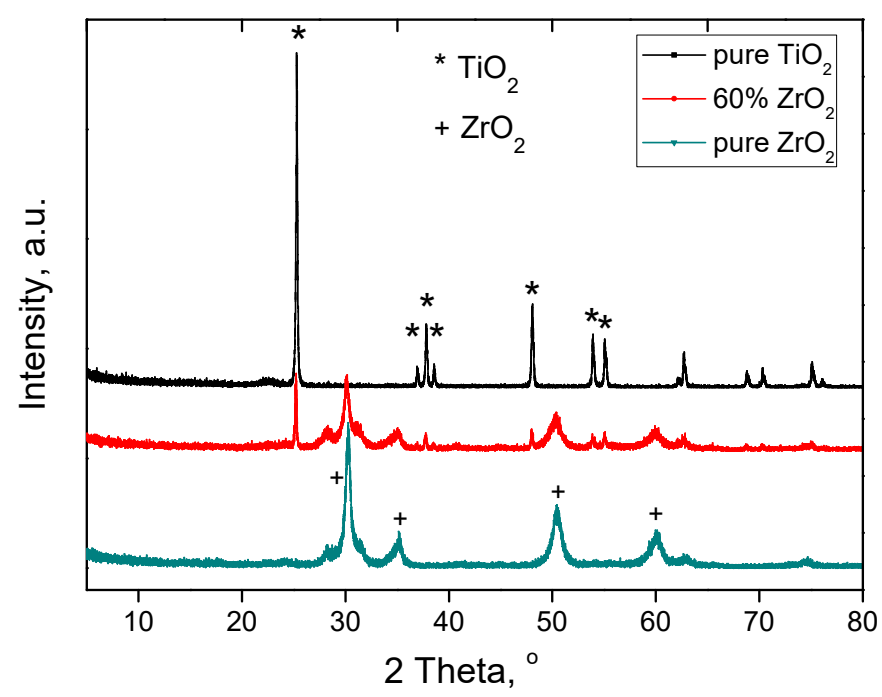

Figure 1. $\mathrm{XRD}$ patterns of $60 \% \mathrm{ZrO}_{2}-\mathrm{TiO}_{2}$ pure $\mathrm{ZrO}_{2}$ and pure $\mathrm{TiO}_{2}$ catalyst. 
The IR spectra of catalysts are shown in Figure 2. The bands at 1044 and $990 \mathrm{~cm}^{-1}$ observed for pure zirconia and $60 \mathrm{wt} . \% \mathrm{ZrO}_{2}-\mathrm{TiO}_{2}$ samples were attributed to the presence of asymmetric and symmetric $S \cdots O$ stretching vibrations, respectively [29]. The signal around $1141 \mathrm{~cm}^{-1}$ was ascribed to the symmetric stretching of $\mathrm{S}=\mathrm{O}$ bond. On the other hand, the band around $1232 \mathrm{~cm}^{-1}$ was attributed to the presence of the asymmetric stretching of the mentioned bond [30]. The band at $1630 \mathrm{~cm}^{-1}$ was ascribed to the "combined symmetric and asymmetric stretching modes" of molecular water connected with sulfated groups [31]. The signals ascribed to the $\mathrm{S}=\mathrm{O}$ bond were not noticed for pure titania sample. The lack of mentioned bands, in this case, results from the fact that the content of sulfate groups existing on the surface of pure titania is too low, which was also confirmed by the catalyst surface acidity test.



Figure 2. IR spectrum of 60 wt. $\% \mathrm{ZrO}_{2}-\mathrm{TiO}_{2}$, pure $\mathrm{TiO}_{2}$ and pure $\mathrm{ZrO}_{2}$.

The studies on the properties of sulfated metal oxides performed by Ward and Ko [32] indicated that their structure includes both types of acid sites (Brønsted acid sites and Lewis acid sites). The weakened $\mathrm{O}-\mathrm{H}$ groups, affected by the presence of neighboring $\mathrm{SO}_{4}{ }^{2-}$ groups, play a role of Brønsted acid sites. On the other hand, the electronically deficient $\mathrm{M}^{4+}$ ions ( $\mathrm{M}=$ zirconium or titanium) can act as Lewis acid sites (this is connected with its electron-withdrawing nature). The performed investigations confirmed that the quantity of Lewis and Brønsted acid sites increases with the rise in the $\mathrm{SO}_{4}{ }^{2-}$ active sites density.

\subsection{Py-GC/MS Results and Discussion}

Py-GC/MS is an instrument for studying the effect of the process condition and different catalysts on the quantities of individual compounds that are formed in pyrolysis. It allows variations of different process parameters, such as heating rate, temperature, pressure, resident time, carrier gas flow composition and carrier gas flow rate in pyrolysis reactor and in catalytic bed. Azzeezet et al. (2010) [33] compared the Py-GC/MS and results from the bench-scale unit and only slight differences in the relative concentration of individual chemicals were found. We can conclude that the Py-GC/MS is an effective method for the research of the reaction mechanism. However, the products from Py-GC/MS cannot be collected. That is why it is not possible to determine a mass balance. Though the instrument does not allow products collection, the changes in peak areas of each chemical compound can be considered to be linear with the number of detected substances. Hence, the change in the total peak area can be used as a good indicator of the total amount of bio-oil formed in the processes carried out at various conditions. 


\subsection{1. $\mathrm{H}_{2}$ and Catalyst Effects on the Overall Yield of M Pyrolysis Vapors}

Figure 3 shows the total chromatographic peak area for the control sample (M pyrolysis in He atmosphere), $\mathrm{M}$ pyrolysis at various $\mathrm{H}_{2}$ pressure, and $\mathrm{M}$ pyrolysis vapor in $\mathrm{He}$ atmosphere cracking on various catalysis. The highest peak area was achieved for the control sample without the catalyst. With the introduction of an acidic catalyst, the total peak area decreased noticeably-which is not surprising, because in the presence of the catalyst the decarbonylation and decarboxylation reactions were prompted [34]. The catalyst will favor cracking of oligomers into monomeric volatile compounds, which enhance the total amount of detectable compounds. However, the catalysts also increase the cracking of those volatile compounds to permanent gas, thus, decrease the overall yield of volatile products. The same phenomenon has also been observed by Ilipoulou et al. [35,36]. $60 \mathrm{wt} . \% \mathrm{ZrO}_{2}-\mathrm{TiO}_{2}$ and pure $\mathrm{ZrO}_{2}$ reduced the total detectable products yield to the greatest extent. This is mainly due to the cracking of volatile compounds; however, polymerization to form char, which is caused by the high acidity of catalysts cannot also be excluded. Zheng et al. [37] suggested that week acid sites facilitate the formation of aromatics, while medium and strong Brönsted acid sites can be responsible for the production of coke.

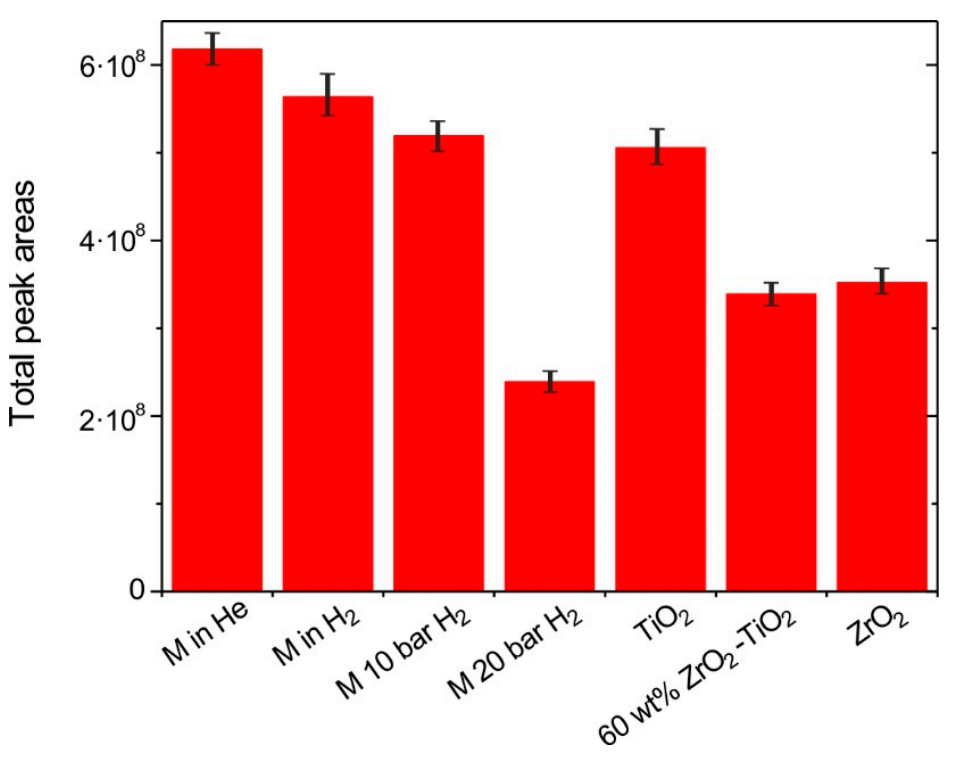

Figure 3. The $\mathrm{H}_{2}$ and catalyst effects on the overall yields.

$\mathrm{H}_{2}$ is reactive and can react with the oxygen compounds in biomass vapors to form water. A largest drop of total peak area took place when 20 bar of $\mathrm{H}_{2}$ is introduced. However, the difference between atmospheric $\mathrm{H}_{2}$ and atmospheric $\mathrm{He}$ is small.

\subsection{2. $\mathrm{H}_{2}$ and Catalyst Effects on Carboxylic Acids}

The carboxylic acids are formed in the ring scission of cellulose. They are responsible for the corrosiveness of bio-oil. The carboxylic acids can also promote reactions, such as polymerization during storage. It is mainly caused by the presence of acetic acid (HAc), which occurs in the greatest content. Therefore, it is extremely important to eliminate this compound to improve the quality of bio-oil.

Figure 4 shows the acetic acid peak areas in different conditions. The HAc yield did not change with the introduction of $\mathrm{TiO}_{2}$, but slightly increased by the $60 \mathrm{wt} . \% \mathrm{ZrO}_{2}-\mathrm{TiO}_{2}$ and $\mathrm{ZrO}_{2}$. It has been reported that the zeolite catalyst elevated the level of carboxylic acid yield [38-40], and they are not favorable for the catalytic cracking of biomass fast pyrolysis vapors. Qiang et al. (2010) [41] studied several different metal oxides, and reported that the $\mathrm{CaO}$ completely eliminated the acids, and that might be related to its strong alkalinity. Additionally, fast pyrolysis experiments performed by Grams et al. demonstrated that an application of $\mathrm{Ni}$ catalysts supported on $\mathrm{Al}_{2} \mathrm{O}_{3}$ allowed for the 
significant reduction of the content of carboxylic acids in the mixture of the formed products, while in the presence of $\mathrm{ZrO}_{2}$ its contribution remained on the moderate level [42].

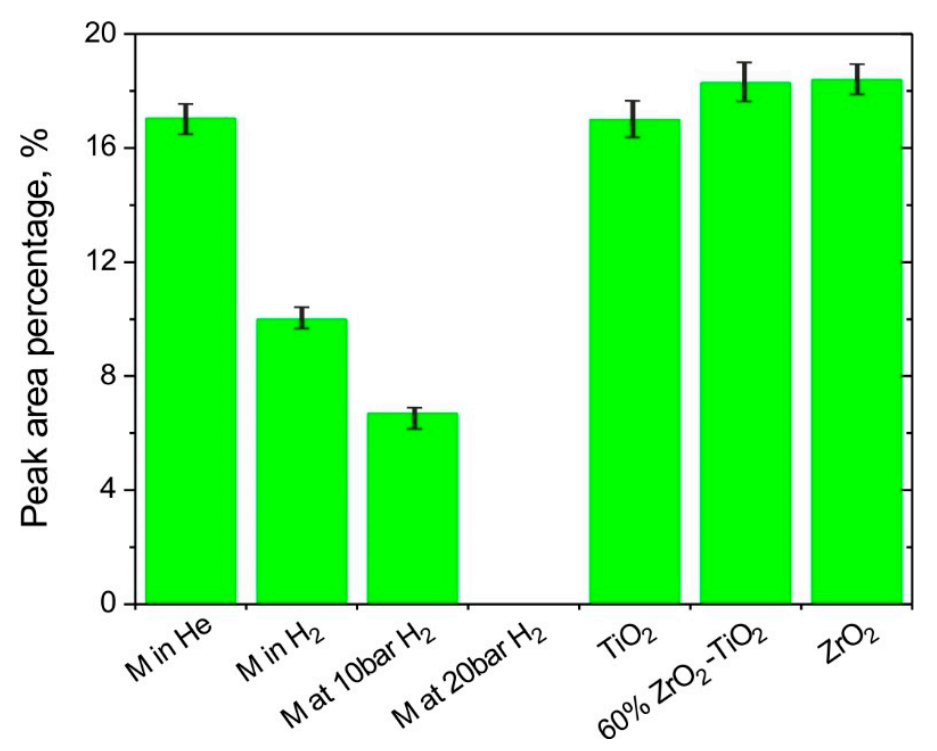

Figure 4. The peak area percentages for HAc.

The Hac yield decreased with increasing $\mathrm{H}_{2}$ pressure. A drop of around $40 \%$ in Hac peak area percentage occurred when atmospheric $\mathrm{H}_{2}$ was introduced compared to the result obtained in He. The Hac content further decreased when the $\mathrm{H}_{2}$ pressue increased to $10 \mathrm{bar}$, and it was eliminated when the pressure reached 20 bar. French and Czernik (2010) [6] showed that the primary degradation products of HAc are likely to be $\mathrm{CO}_{2}$; the other products are water and coke. We can conclude that the acidic catalysts are not favorable for the decarboxylation or dehydration of $\mathrm{HAc} . \mathrm{H}_{2}$ plays a very important role in the reduction of carboxylic acids in biomass pyrolysis vapors.

\subsection{3. $\mathrm{H}_{2}$ and Catalyst Effects on Phenol Derivatives}

Phenol derivates are the most valuable products in biomass pyrolysis vapors. The volatile monomeric phenolics can be obtained by the degradation of lignin and, to a lesser extent, hemicelluloses. Lignin is the most heat resistant of the three lignocellulosic feedstock components. Thus, mainly char was produced during pyrolysis, and at the same time, the larger and heavier non-volatile oligomers are also generated. The oligomers are non-volatile, thermally unstable and cause rapidly polymerization to form coke on the catalyst surface, resulting in catalyst deactivation. However, it is wiser to convert them into monomerics rather than removing them from biomass vapors, since they have higher heating values with a lower oxygen content [2].

According to Reference [43], the formed phenolic compounds can be assigned to different fractions (such as guaiacol-type, phenol-type, syringol-type, catechol-type, cresol-type, and other-type compounds). Their contribution can change with the increase in the pyrolysis temperature, which enhances the formation of the phenol-type, cresol-type and catechol-type compounds. This phenomenon indicates that demethoxylation, demethylation and alkylation reactions can occur simultaneously at high temperatures [44]. Further increase in the pyrolysis temperature can enhance not only demethylation and demethoxylation, but also decarboxylation, and alkylation reactions which results in the change of the distribution of pyrolysis products toward alkylphenol and polyhydroxybenzene, as mentioned in Reference [45].

Figure 5 shows that the total amounts of phenol derivates were increased with $\mathrm{TiO}_{2}$ content, indicating there are more monomerics formed from the oligomers. Moreover, the low molecular weight phenols (MW < 150) (Figure 5a) and high molecular weight phenols (MW > 150) (Figure 5b) were both enhanced by this acidic catalyst. The catalyst is responded for oligomers cracking into monomerics 
and bigger phenolics further cracking into smaller phenolics improvement. The total low MW phenols peak areas of $60 \mathrm{wt} . \% \mathrm{ZrO}_{2}-\mathrm{TiO}_{2}$ and $\mathrm{TiO}_{2}$ were $9.7 \%$ and $8.4 \%$, respectively. They were both higher than that obtained in the absence of the catalyst. The low overall phenolics yield observed for $60 \mathrm{wt} . \%$ $\mathrm{ZrO}_{2}-\mathrm{TiO}_{2}$ resulted in the significantly lower yield of the high $\mathrm{MW}$ compounds. This might be due to the higher acidity of $60 \mathrm{wt} . \% \mathrm{ZrO}_{2}-\mathrm{TiO}_{2}$. As a result, the strong acidic catalysts may not be suitable for the production of phenolics. On the other hand, it is expected the average molecular weight, and the viscosity of the bio-oil can be reduced with the dramatic decrease of heavy phenolics.
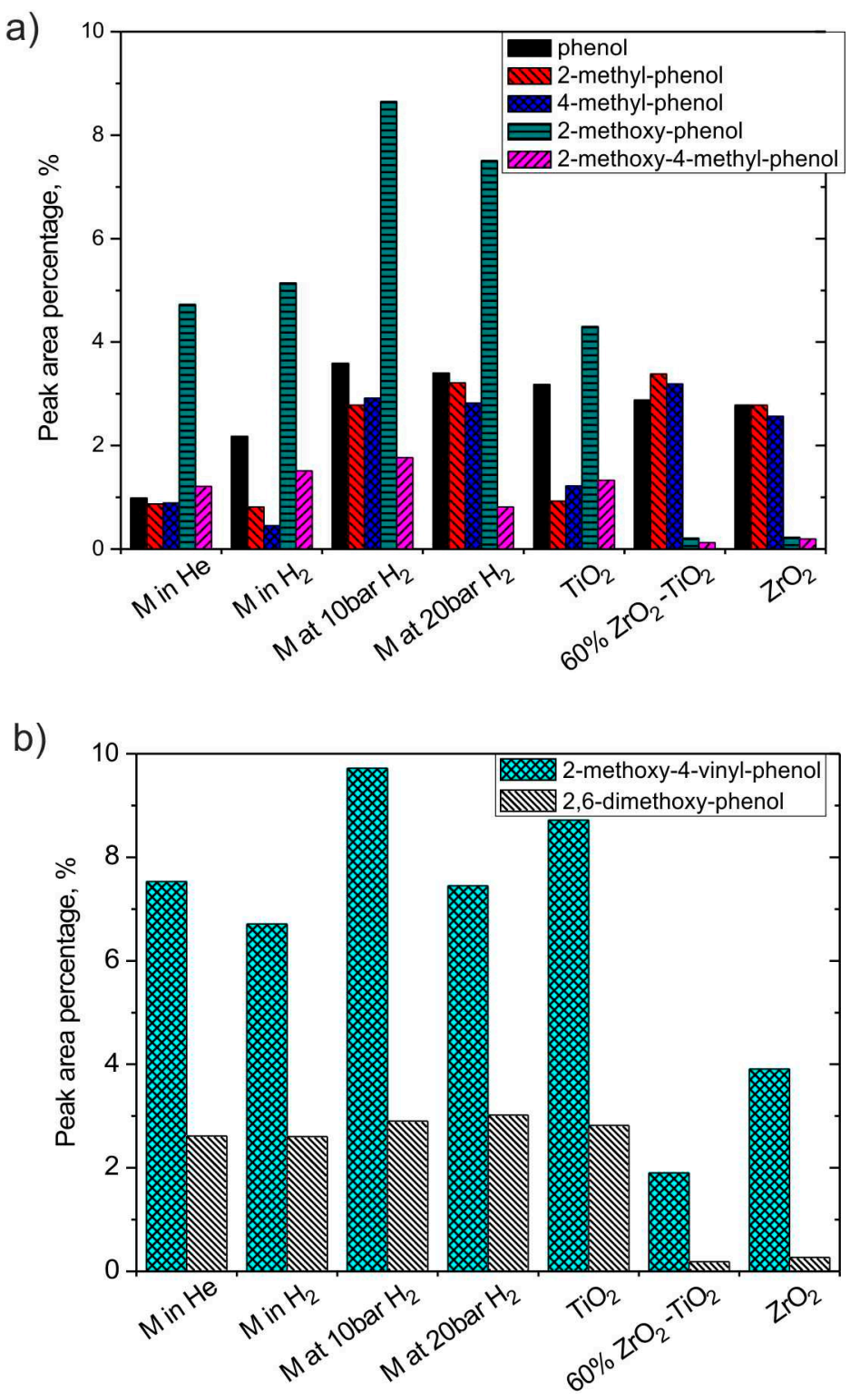

Figure 5. The peak area percentage of phenol derivatives (a) low MW phenolics, (b) high MW phenolics.

The effects of $\mathrm{H}_{2}$ pressure on the phenolics were shown in Figure 5. The pressurized hydrogen favored a higher overall phenol yield. Pandey et al. (2011) [22] and Melligan et al. (2013) [46] also reported that the introduction of $\mathrm{H}_{2}$ would help the degradation of lignin. The highest yield of phenolics was achieved when the $\mathrm{H}_{2}$ pressure was increased to 10 bar, which almost doubles the phenolics yield compared to the result observed at He atmosphere. However, a slight decrease in the yields of phenols occurred with a further increase in $\mathrm{H}_{2}$ pressure. This is because the phenolics are further converted into aromatic hydrocarbons or cyclohexane. The possible HDO mechanisms of two 
typical phenol derivatives (alkyl-substituted phenol derivative, i.e., cresol, and methoxy substituted phenol derivative, i.e., guaiacol) are presented in the literature $[7,47,48]$, and summarized in Figure 6 . One way is to convert cresol into toluene by directly dehydroxylation; the other is to saturate the aromatic ring then further convert to form cylcohexane. Senol et al. (2007) [47] reported ring saturation happened before the cleavage of the $\mathrm{C}-\mathrm{O}$ bond during HDO of phenol. The unsaturated aromatics have a much higher octane value and avoiding the saturation also hydrogen consumption can be minimized [49]. The resulting compounds from the ring saturation or cleavage of C-O bond are derivatives of cyclohexane and toluene. The two parallel reaction pathways for guaiacol in HDO are: The direct demethoxylation to form phenol and the demethylation, followed by substitution and dehydration to form phenol and alkyl-substituted phenols [7,48]. From the results, we can predict that with the rise of $\mathrm{H}_{2}$ pressure, not only the lignin degradation will grow, but also the yield of aromatic hydrocarbons and cyclo-alkanes will increase.

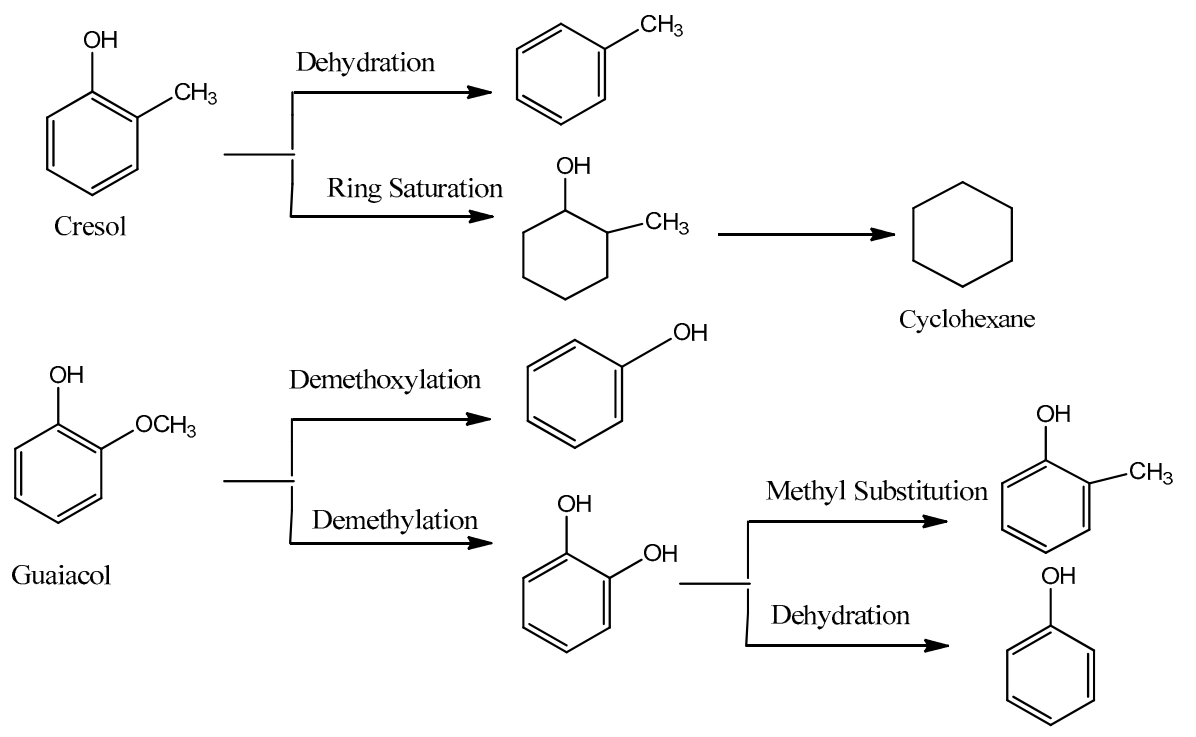

Figure 6. The possible mechanism routes for phenol monomers.

\subsubsection{The effect of $\mathrm{H}_{2}$ and Catalysts on Aromatic Hydrocarbons}

As mentioned earlier, the two parallel pathways of HDO of phenols can be distinguished: (i) Direct deoxygenation (DDO) which allows for maintaining the aromatic character of formed products; and (ii) hydrogenation (HYD) where aromatic ring is hydrogenated, and the final compounds are saturated [21]. According to Ruddy et al. (2014) [50], the conversion of phenol by DDO leads to the formation of benzene by the cleavage of $\mathrm{C}-\mathrm{O}$ bond. HYD results in hydrogenation of aromatic ring to cyclohexanol. Subsequently, hydrogenation of benzene or deoxygenation of cyclohexanol can occur giving cyclohexane.

Figure 7 demonstrates the influence of both hydrogen pressure and catalysts on the formation of the aromatic compounds. In a He atmosphere and in the absence of catalysts, the pyrolysis of biomass produced trace number of aromatic hydrocarbons, and neither benzene nor xylene was detected. The hydrocarbon yields slightly changed with the addition of $\mathrm{TiO}_{2}$. However, $60 \mathrm{wt}$. $\% \mathrm{ZrO}_{2}-\mathrm{TiO}_{2}$ and $\mathrm{ZrO}_{2}$ greatly enhanced the total peak area percentage of hydrocarbons, and toluene is the most abundant aromatic hydrocarbon in the catalytic products. The results of Py/GC-MS experiments indicate that the catalyst with stronger acidity will promote the deoxygenation of biomass vapors to form hydrocarbons. Similar results were also observed by other studies [41,51]. The same phenomenon was described Grams et al. (2015) [42]. However, it was demonstrated that in this case not only acidity, but also other factors (such as surface area, type of the used precursor, and crystallographic structure of the catalyst) could be very important in the production of different types of hydrocarbons. 




Figure 7. The peak area percentage of aromatic hydrocarbons.

The studies conducted by Bui et al. [7] demonstrated the effect of the support of CoMoS catalyst on their performance in HDO of guaiacol. The authors showed that there are two reaction pathways of guaiacol conversion. In the first one phenol can be obtained directly by demethoxylation, while in the second demethylation takes place leading to the formation of catechol as an intermediate, which can be transformed via methyl substitution and dehydration to phenol and alkyl-substituted phenols.

Described results revealed that for the catalyst supported on $\mathrm{Al}_{2} \mathrm{O}_{3}$ catechol and phenol were obtained at low conversion rates, in the case of the catalyst supported on $\mathrm{TiO}_{2}$ only catechol was formed at low conversion rates, while for the catalyst supported on $\mathrm{ZrO}_{2}$ phenol was the main product of the reaction. Moreover, in the last case, a much higher benzene yield was observed in comparison to other catalysts. This trend is in agreement with our investigations in which the presence of $\mathrm{ZrO}_{2}$ allowed for the production of higher benzene yield in comparison to pure $\mathrm{TiO}_{2}$.

The introduction of hydrogen significantly increased the aromatic hydrocarbons yield by hydrogenation. However, a rise in $\mathrm{H}_{2}$ pressure from atmospheric to 10 bar caused a slight decrease in the yield of aromatic hydrocarbons. This drop becomes more evident when the hydrogen pressure was raised to 20 bar. The increasing pressure of $\mathrm{H}_{2}$ enhances the ring saturation and direct elimination of hydroxyl group by hydrogenolysis.

The overall yields of aromatic hydrocarbons with the addition of $\mathrm{H}_{2}$ are lower than the yield obtained by introduction of acidic catalysts. The result indicates the dehydration, decarboxylation, and decarbonylation reactions of biomass vapors lead to form hydrocarbons. The reactions were primarily promoted by Bronsted acid sites and to a lesser extent by $\mathrm{H}_{2}$. The possible mechanisms of the formation of aromatic hydrocarbons from phenols and their conversion to cyclo-alkanes are shown in Figure 8. 


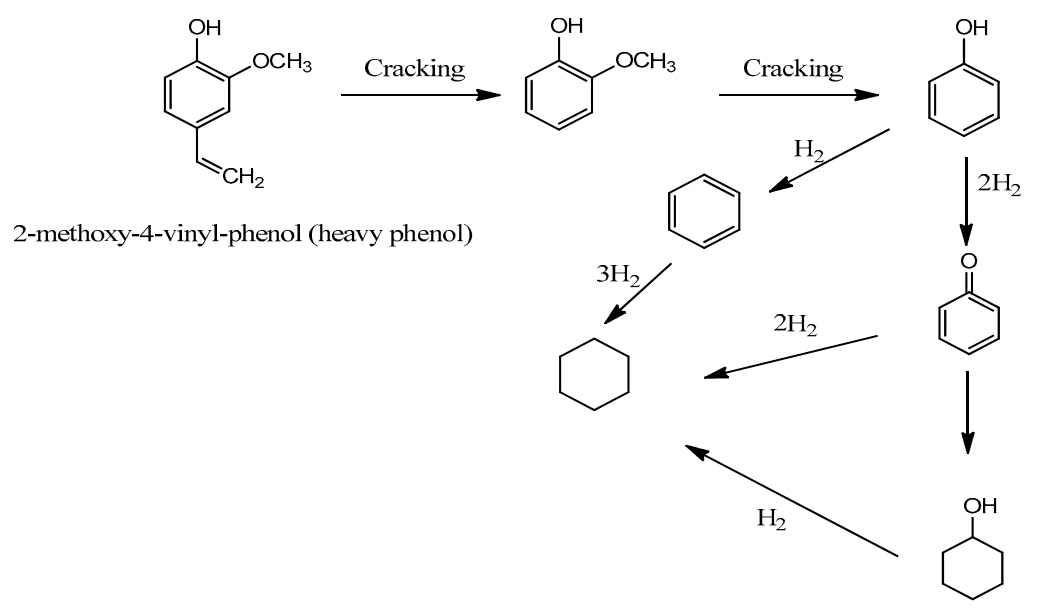

Figure 8. The suggested mechanism for converting heavy phenol to benzene and cyclohexane.

\subsubsection{The Effect of $\mathrm{H}_{2}$ and Catalysts on Cyclo-Alkanes}

According to Ruddy et al. [51], the formation of cyclo-hydrocarbons requires initial hydrogenation of aromatic $\mathrm{C}-\mathrm{C}$ bonds and carbonyl $\mathrm{C}-\mathrm{O}$ bonds, and subsequent dehydration of the formed alcohol. Cyclo-hydrocarbons are one of the most important products in biomass pyrolysis vapors, as they have good fuel properties with a high energy level. However, the fast pyrolysis of lignocellulosic biomass only generates a minor number of cyclo-hydrocarbons. It is important to find a proper method to improve their yield. Figure $9 a, b$ indicates the effects of catalysts on cyclo-hydrocarbons are negligible. However, $\mathrm{H}_{2}$ plays a very important role in the hydrogenation of aromatic hydrocarbons to form cyclo-hydrocarbons. The maximum yield was achieved when the $\mathrm{H}_{2}$ rise to 20 bar.

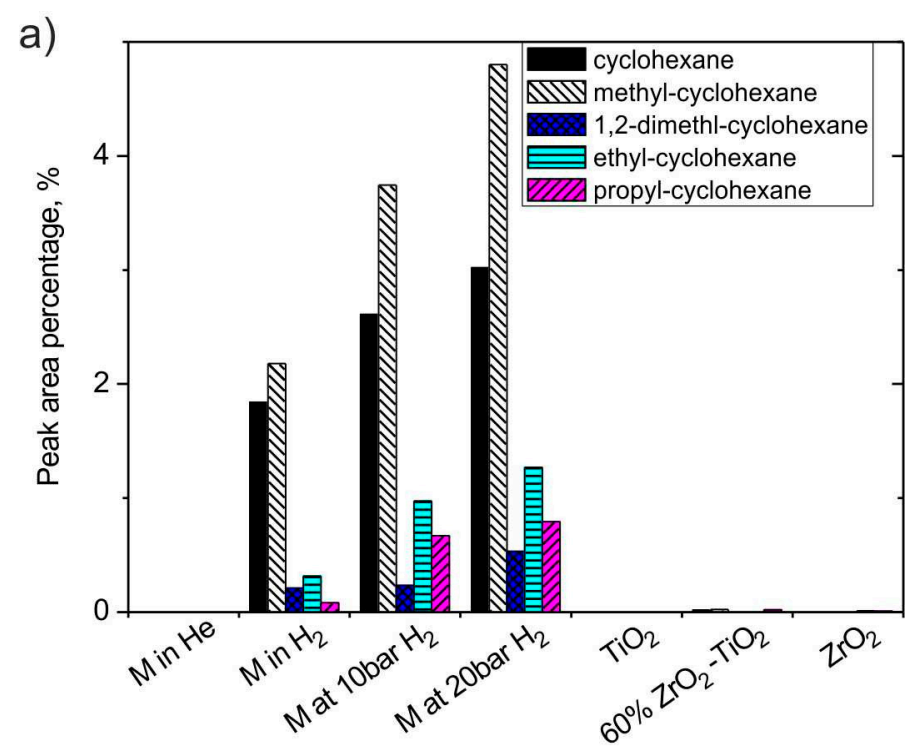

Figure 9. Cont. 


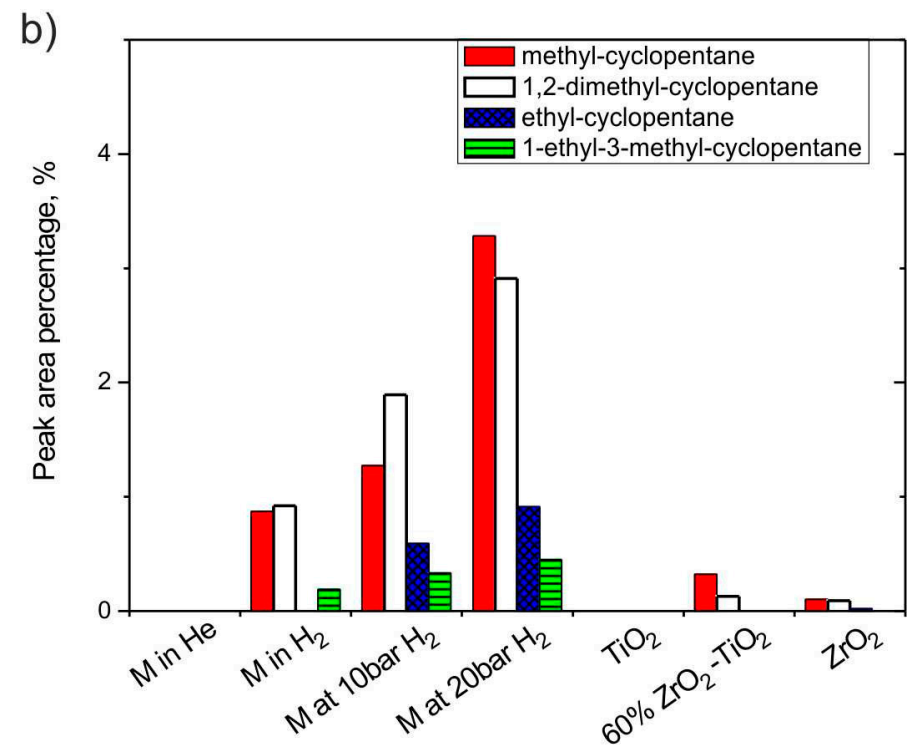

Figure 9. The peak area percentages of cyclo-alkanes: (a) cyclohexane derivatives, and (b) cyclopentane derivatives.

\subsubsection{The Effect of $\mathrm{H}_{2}$ and Catalysts on Furan Derivatives and Alcohols}

The effect of $\mathrm{H}_{2}$ on furan derivates and alcohols are shown in Figure 10a,b, respectively. Furan compounds are good platform chemicals, thus, increasing the yield of furans can enhance the value of bio-oil. Furans are derived from the dehydration of cellulose and hemicelluloses. The overall furan yields increased with the introduction of a catalyst. The light furans content was increased by catalysts, but heavier one (2-ethyl-5-methyl-furan) decreased. This result indicates that heavy furan will undergo secondary cracking into light furans with the acidic catalyst. With the increase of the acidity of catalysts, the yield of heavy furan decreased, which confirms the cracking is promoted in the acid-catalyzed condition.

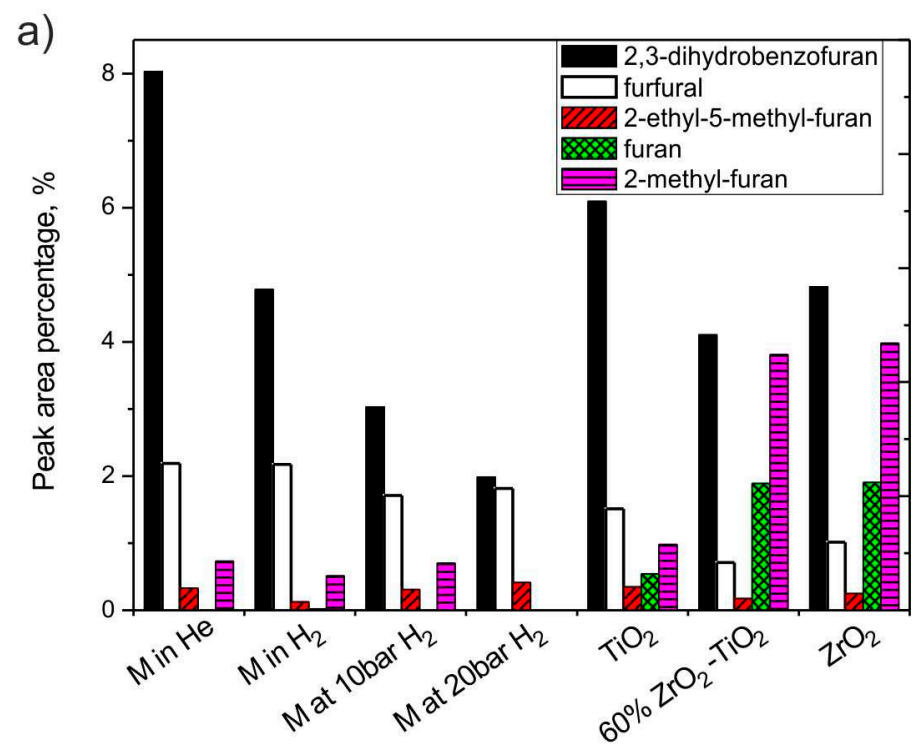

Figure 10. Cont. 




Figure 10. (a) The peak area percentages of furans; (b) The peak area percentages of alcohols.

Alcohols are perfect fuel additives, as they are derived from the hydrothermal degradation of cellulose and hemicellulose. Under the $\mathrm{H}_{2}$ condition, alcohols can be produced from the hydrogenation of carbonyl compounds. Furfural is another resource for light alcohols-in this case, the process can go through decarbonylation and hydrogenation to form butanol and pentanol, as described by Melligan et al. (2013) [46]. Moreover, it is observed that with the $\mathrm{H}_{2}$ pressure increase, both butanol and pentanol yield grow.

\subsection{The Comparison of Catalytic Cracking and Hydrogenation}

Sulfated $60 \mathrm{wt} . \% \mathrm{ZrO}_{2}-\mathrm{TiO}_{2}$ (cat) was the only catalyst applied in the fast pyrolysis study of three feedstocks. Figure 11 shows the total peak area of the different feedstocks handled to various treatments. Lignin and HR have quite low pyrolysis products yield compared with the total peak area of M. During the acid hydrolysis process, though most of the carbohydrates were diluted into the acid solution, some small amount of them was reacted and bound to lignin. This amount of sugars is the reason for the presence of acetic acid in HR pyrolysis vapors.

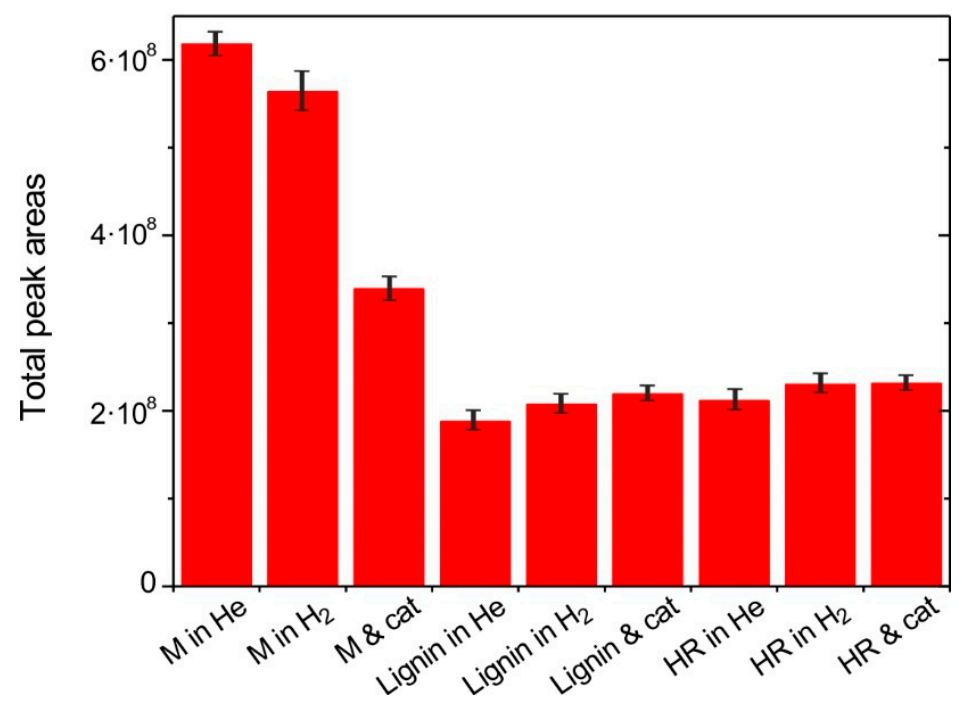

Figure 11. Effects of $\mathrm{H}_{2}$ and catalyst on different feedstock. 
Overall yields of lignin and HR were enhanced by the introduction of $\mathrm{H}_{2}$ or catalysts. This is because there are more oligomers in the lignin, which are not easy to break down to volatile monomerics. The catalysts boosted the cracking of those oligomers into smaller monomerics phenolics more than the polymerization. $\mathrm{H}_{2}$ also helped the decomposition of lignin by dehydration and hydrogenation. The results indicate it is more beneficial for HR to undergo hydro-pyrolysis or catalytic pyrolysis than the ambient pyrolysis.

The specific phenols, aromatic hydrocarbons and cyclo-alkanes yields are shown in Table 3. It can be noticed that with the introduction of $\mathrm{H}_{2}$, the percentage of light phenols increased for all feedstock, and the trends among three feedstocks are similar. The overall phenol percentage of lignin in ambient $\mathrm{H}_{2}$ is $46.1 \%$, followed by $35.1 \%$ of $\mathrm{HR}$, which are both higher than the phenol yield from $\mathrm{M}$, which is only $20.5 \%$. However, the overall aromatic hydrocarbons and cyclo-alkanes yields of HR are slightly less than from $\mathrm{M}$. This result indicates the HR has the potential to become a resource for phenol production.

Table 3. Peak area percentages for the acetic acid, phenols, aromatics hydrocarbons and cyclo-alkanes (the accuracy was in a range of $2 \%$ ).

\begin{tabular}{|c|c|c|c|c|c|c|c|c|c|}
\hline \multirow{2}{*}{ Components wt. $\%$} & \multicolumn{3}{|c|}{ Miscanthus } & \multicolumn{3}{|c|}{ Lignin } & \multicolumn{3}{|c|}{ Hydrolysis Residue } \\
\hline & He & $\mathbf{H}_{2}$ & cat & $\mathrm{He}$ & $\mathbf{H}_{2}$ & cat & $\mathrm{He}$ & $\mathbf{H}_{2}$ & cat \\
\hline acetic acid & 17.0 & 9.98 & 18.28 & 0 & 0 & 0 & 5.99 & 3.81 & 5.72 \\
\hline 2-methyl-phenol & 0.87 & 0.81 & 3.38 & 2.27 & 1.81 & 3.21 & 1.37 & 1.89 & 1.09 \\
\hline 4-methyl-phenol & 0.89 & 0.45 & 3.19 & 1.73 & 4.32 & 3.12 & 3.46 & 3.82 & 3.01 \\
\hline 4-ethyl phenol & 0.12 & 0.18 & 0.67 & 0.04 & 0.00 & 1.89 & 2.70 & 2.18 & 3.90 \\
\hline 2-methoxy-4-methyl-pheonl & 1.21 & 1.51 & 0.12 & 0.13 & 0.29 & 1.29 & 2.70 & 4.29 & 2.78 \\
\hline 2-methoxy-4-ethyl-pheonl & 1.16 & 1.00 & 0.91 & 0.76 & 0.19 & 1.09 & 1.55 & 1.52 & 1.67 \\
\hline low MW phenols $(\mathrm{MW}<150)$ & 9.97 & 11.2 & 11.3 & 26.59 & 35.0 & 35.9 & 22.09 & 27.6 & 28.3 \\
\hline 2-methoxy-4-vinyl-phenol & 7.53 & 6.71 & 1.90 & 5.37 & 5.21 & 3.21 & 2.99 & 3.90 & 1.18 \\
\hline 2,6-dimethoxy-phenol & 2.30 & 2.60 & 0.19 & 5.67 & 5.91 & 4.91 & 2.62 & 3.67 & 1.90 \\
\hline p-xylene & 0.00 & 1.21 & 2.78 & 0.37 & 1.08 & 3.09 & 0.00 & 0.80 & 1.71 \\
\hline 1-ethyl-methyl-benzene & 0.04 & 0.00 & 1.02 & 0.32 & 1.09 & 1.11 & 0.08 & 0.19 & 0.79 \\
\hline aromatic hydrocarbons & 0.32 & 6.40 & 12.0 & 1.93 & 7.31 & 10.9 & 0.89 & 5.89 & 7.52 \\
\hline cyclohexane & 0 & 1.84 & 0.02 & 0 & 2.20 & 0.00 & 0 & 2.53 & 0.11 \\
\hline methyl-cyclohexane & 0 & 2.18 & 0.02 & 0 & 3.29 & 0.00 & 0 & 1.24 & 0.02 \\
\hline 1,2-dimethl-cyclohexane & 0 & 0.21 & 0 & 0 & 1.02 & 0.09 & 0 & 0.01 & 0.07 \\
\hline ethyl-cyclohexane & 0 & 0.32 & 0 & 0 & 0 & 0 & 0 & 0.61 & 0.02 \\
\hline propyl-cyclohexane & 0 & 0.08 & 0.02 & 0 & 1.90 & 0.39 & 0.25 & 0.19 & 0 \\
\hline methyl-cyclopentane & 0 & 0.87 & 0.32 & 0 & 2.10 & 0.19 & 0 & 0.67 & 0.52 \\
\hline 1,2-dimethyl-cyclopentane & 0 & 0.92 & 0.13 & 0 & 0 & 0.28 & 0 & 0.82 & 0 \\
\hline cyclo alkanes & 0 & 6.42 & 0.51 & 0.00 & 10.5 & 0.95 & 0.25 & 6.07 & 0.74 \\
\hline
\end{tabular}

The formation of similar products of fast pyrolysis of various types of biomass has also been observed by other researchers [52-54]. Mullen and Boateng [55] proved that the number of produced hydrocarbons is noticeably higher in the case of decomposition of the feedstock containing cellulose than that obtained for lignin. Moreover, Stefanidis et al. [56] confirmed that the presence of acidic catalysts enhances the production of aromatics, while their content was negligible after the non-catalytic reaction.

\section{Conclusions}

Three metal oxide-based catalysts and three different $\mathrm{H}_{2}$ pressures was applied in miscanthus fast pyrolysis vapor upgrading in this study. Addition of $\mathrm{H}_{2}$ and increasing its pressure results in compositions of fast pyrolysis vapors improvements by raising amount of alcohols and cyclo-hydrocarbons. Sulfated $60 \mathrm{wt} . \% \mathrm{ZrO}_{2}-\mathrm{TiO}_{2}$ catalyst shows the best catalytic activity in producing monomeric phenols among all catalysts, the reduction of heavy compounds lower the average molecular 
weight and viscosity of bio-oil. The aromatic hydrocarbons yields were also increased by every of the catalyst applied. The strong acidity of the catalysts promoted the cracking, HDO and decarboxylation.

Additionally, pure lignin and HR were also tested and compared with $\mathrm{M}$ to study the possibility of using HR as a phenolic resource. HR is composed of $44 \mathrm{wt} . \%$ lignin, giving a yield of $43 \mathrm{wt} . \%$ phenols during pyrolysis compared with a yield of $26 \mathrm{wt} . \%$ from $\mathrm{M}$. The result indicates HR has the potential to become a source of phenols.

Author Contributions: Y.L. conducted experimental and analytical, and took part in writing. J.J.L. and J.G. were involved in results interpretation and corrected the discussion in the manuscript. W.K. developed work concept, took part in writing, discussion and correction of the manuscript.

Funding: This research received no external funding.

Conflicts of Interest: The authors declare no conflict of interest.

\section{References}

1. Ahorsu, R.; Medina, F.; Constanti, M. Significance and Challenges of Biomass as a Suitable Feedstock for Bioenergy and Biochemical Production: A Review. Energies 2018, 11, 3366. [CrossRef]

2. Lu, Q.; Zhang, Y.; Tang, Z.; Li, W.Z.; Zhu, X.F. Catalytic upgrading of biomass fast pyrolysis vapors with titania and zirconia/titania based catalysts. Fuel 2010, 89, 2096-2103. [CrossRef]

3. Olazar, M.; Aguado, R.; Bilbao, J.; Barona, A. Pyrolysis of sawdust in a conical spouted-bed reactor with a HZSM-5 catalyst. Aiche J. 2000, 46, 1025-1033. [CrossRef]

4. Elliott, D.C.; Hart, T.R.; Neuenschwander, G.G.; Rotness, L.J.; Olarte, M.V.; Zacher, A.H.; Solantausta, Y. Catalytic Hydroprocessing of Fast Pyrolysis Bio-oil from Pine Sawdust. Energy Fuels 2012, 26, 3891-3896. [CrossRef]

5. Grams, J.N.M.; Ruppert, A.M.; Kwapinski, W. Catalytic performance of Ni catalyst supported on $\mathrm{CeO}_{2}$, $\mathrm{ZrO}_{2}$ and $\mathrm{CeO}_{2}-\mathrm{ZrO}_{2}$ in the upgrading of cellulose fast pyrolysis vapors. Comptes Rendus Chim. 2015, 18, 1223-1228. [CrossRef]

6. French, R.; Czernik, S. Catalytic pyrolysis of biomass for biofuels production. Fuel Process. Technol. 2010, 91, 25-32. [CrossRef]

7. Bui, V.N.; Laurenti, D.; Delichere, P.; Geantet, C. Hydrodeoxygenation of guaiacol Part II: Support effect for CoMoS catalysts on HDO activity and selectivity. Appl. Catal. B-Environ. 2011, 101, 246-255. [CrossRef]

8. Kaewpengkrow, P.; Atong, D.; Sricharoenchaikul, V. Catalytic upgrading of pyrolysis vapors from Jatropha wastes using alumina, zirconia and titania based catalysts. Bioresour. Technol. 2014, 163, 262-269. [CrossRef]

9. Lu, Q.; Zhang, Z.B.; Wang, X.Q.; Dong, C.Q.; Liu, Y.Q. Catalytic upgrading of biomass fast pyrolysis vapors using ordered mesoporous $\mathrm{ZrO}_{2}, \mathrm{TiO}_{2}$ and $\mathrm{SiO}_{2}$. In Proceedings of the International Conference on Applied Energy (Icae2014), Taipei, Taiwan, 30 May-2 June 2014; pp. 1937-1941.

10. Wachala, M.; Grams, J.; Kwapinski, W.; Ruppert, A.M. Influence of $\mathrm{ZrO}_{2}$ on catalytic performance of $\mathrm{Ru}$ catalyst in hydrolytic hydrogenation of cellulose towards gamma-valerolactone. Int. J. Hydrogen Energy 2016, 41, 8688-8695. [CrossRef]

11. Maity, S.K.; Rana, M.S.; Bej, S.K.; Ancheyta, J.; Dhar, G.M.; Rao, T. $\mathrm{TiO}_{2}-\mathrm{ZrO}_{2}$ mixed oxide as a support for hydrotreating catalyst. Catal. Lett. 2001, 72, 115-119. [CrossRef]

12. Zhang, X.H.; Long, J.X.; Kong, W.; Zhang, Q.; Chen, L.G.; Wang, T.J; Ma, L.L.; Li, Y.P. Catalytic Upgrading of Bio-oil over Ni-Based Catalysts Supported on Mixed Oxides. Energy Fuels 2014, 28, 2562-2570. [CrossRef]

13. Ruppert, A.; Paryjczak, T. Pt/ $\mathrm{ZrO}_{2} / \mathrm{TiO}_{2}$ catalysts for selective hydrogenation of crotonaldehyde: Tuning the SMSI effect for optimum performance. Appl. Catal. A-Gen. 2007, 320, 80-90. [CrossRef]

14. Liu, Y.; Li, Z.; Leahy, J.J.; Kwapinski, W. Catalytically upgrading bio-oil via esterification. Energy Fuel 2015, 29, 3691-3698. [CrossRef]

15. Refaat, A.A. Biodiesel production using solid metal oxide catalysts. Int. J. Environ. Sci. Technol. 2011, 8, 203-221. [CrossRef]

16. Zhang, S.P.; Yan, Y.J.; Li, T.C.; Ren, Z.W. Upgrading of liquid fuel from the pyrolysis of biomass. Bioresour. Technol. 2005, 96, 545-550. [CrossRef] [PubMed]

17. Xu, Y.; Wang, T.J; Ma, L.L.; Zhang, Q.; Liang, W. Upgrading of the liquid fuel from fast pyrolysis of biomass over MoNi/gamma-Al2O3 catalysts. Appl. Energy 2010, 87, 2886-2891. [CrossRef] 
18. Li, H.; Riisager, A.; Saravanamurugan, S.; Pandey, A.; Sangwan, R.S.; Yang, S.; Luque, R. Carbon-Increasing Catalytic Strategies for Upgrading Biomass into Energy-Intensive Fuels and Chemicals. ACS Catal. 2018, 8, 148-187. [CrossRef]

19. Mortensen, P.M.; Grunwaldt, J.D.; Jensen, P.A.; Knudsen, K.G.; Jensen, A.D. A review of catalytic upgrading of bio-oil to engine fuels. Appl. Catal. A-Gen. 2011, 407, 1-19. [CrossRef]

20. Mendes, M.J.; Santos, O.A.A.; Jordao, E.; Silva, A.M. Hydrogenation of oleic acid over ruthenium catalysts. Appl. Catal. A-Gen. 2001, 217, 253-262. [CrossRef]

21. Bu, Q.; Lei, H.W.; Zacher, A.H.; Wang, L.; Ren, S.J.; Liang, J.; Wei, Y.; Liu, Y.P.; Tang, J.M.; Zhang, Q.; et al. A review of catalytic hydrodeoxygenation of lignin-derived phenols from biomass pyrolysis. Bioresour. Technol. 2012, 124, 470-477. [CrossRef]

22. Pandey, M.P.; Kim, C.S. Lignin Depolymerization and Conversion: A Review of Thermochemical Methods. Chem. Eng. Technol. 2011, 34, 29-41. [CrossRef]

23. Huber, G.W.; Iborra, S.; Corma, A. Synthesis of transportation fuels from biomass: Chemistry, catalysts, and engineering. Chem. Rev. 2006, 106, 4044-4098. [CrossRef] [PubMed]

24. Danalatos, N.G.; Archontoulis, S.V.; Mitsios, I. Potential growth and biomass productivity of Miscanthus $\mathrm{x}$ giganteus as affected by plant density and $\mathrm{N}$-fertilization in central Greece. Biomass Bioenergy 2007, 31, 145-152. [CrossRef]

25. Dussan, K.; Girisuta, B.; Haverty, D.; Leahy, J.J.; Hayes, M.H. Kinetics of levulinic acid and furfural production from Miscanthus x giganteus. Bioresour Technol. 2013, 149, 216-224. [CrossRef] [PubMed]

26. Xue, G.; Kwapinska, M.; Kwapinski, W.; Czajka, K.M.; Kennedy, J.; Leahy, J.J. Impact of torrefaction on properties of Miscanthus x giganteus relevant to gasification. Fuel 2014, 121, 189-197. [CrossRef]

27. Wang, X.H.; Li, J.G.; Kamiyama, H.; Ishigaki, T. Fe-doped $\mathrm{TiO}_{2}$ nanopowders by oxidative pyrolysis of organometallic precursors in induction thermal plasma: Synthesis and structural characterization. Thin Solid Films 2006, 506-507, 278-282. [CrossRef]

28. Peng, L.; Zhuang, J.; Lin, L. Effects of $\mathrm{Zr} / \mathrm{Ti}$ molar ratio in $\mathrm{SO}^{2-}{ }_{4} / \mathrm{ZrO}_{2}-\mathrm{TiO}_{2}$ calcined at different temperatures on its surface properties and glucose reactivity in near-critical methanol. J. Nat. Gas Chem. 2012, 21, 138-147. [CrossRef]

29. Noda, L.K.; de Almeida, R.M.; Probst, L.F.D.; Gonçalves, N.S. Characterization of sulfated $\mathrm{TiO}_{2}$ prepared by the sol-gel method and its catalytic activity in the n-hexane isomerization reaction. J. Mol. Catal. A Chem. 2005, 225, 39-46. [CrossRef]

30. Babou, F.; Coudurier, G.; Vedrine, J.C. Acidic Properties of Sulfated Zirconia-An Infrared Spectroscopic Study. J. Catal. 1995, 152, 341-349. [CrossRef]

31. Ramadan, A.R.; Yacoub, N.; Bahgat, S.; Ragai, J. Surface and acidic properties of mixed titanium and zirconium sulfated oxides. Colloids Surf. A Physicochem. Eng. Asp. 2007, 302, 36-43. [CrossRef]

32. Ward, D.A.; Ko, E.I. One-step synthesis and characterization of zirconia-sulfate aerogels as solid superacids. J. Catal. 1994, 150, 18-33. [CrossRef]

33. Azeez, A.M.; Meier, D.; Odermatt, J.; Willner, T. Fast Pyrolysis of African and European Lignocellulosic Biomasses Using Py-GC/MS and Fluidized Bed Reactor. Energy Fuels 2010, 24, 2078-2085. [CrossRef]

34. Siddiqui, M.N. Catalytic pyrolysis of Arab Heavy residue and effects on the chemistry of asphaltene. J. Anal. Appl. Pyrolysis 2010, 89, 278-285. [CrossRef]

35. Iliopoulou, E.F.; Stefanidis, S.D.; Kalogiannis, K.G.; Delimitis, A.; Lappas, A.A.; Triantafyllidis, K.S. Catalytic upgrading of biomass pyrolysis vapors using transition metal-modified ZSM-5 zeolite. Appl. Catal. B Environ. 2012, 127, 281-290. [CrossRef]

36. Mante, O.D.; Agblevor, F.A.; Oyama, S.T.; McClung, R. Catalytic pyrolysis with ZSM-5 based additive as co-catalyst to Y-zeolite in two reactor configurations. Fuel 2014, 117, 649-659. [CrossRef]

37. Zheng, A.; Zhao, Z.; Chang, S.; Huang, Z.; Wu, H.; Wang, X.; He, F.; Li, H. Effect of crystal size of ZSM-5 on the aromatic yield and selectivity from catalytic fast pyrolysis of biomass. J. Mol. Catal. A Chem. 2014, 383-384, 23-30. [CrossRef]

38. Qiang, L.; Wen-Zhi, L.; Dong, Z.; Xi-Feng, Z. Analytical pyrolysis gas chromatography mass spectrometry Py-GC/MS of sawdust with Al/SBA-15 catalysts. J. Anal. Appl. Pyrolysis 2009, 84, 131-138. [CrossRef]

39. Wang, D.; Xiao, R.; Zhang, H.; He, G. Comparison of catalytic pyrolysis of biomass with MCM-41 and CaO catalysts by using TGA-FTIR analysis. J. Anal. Appl. Pyrolysis 2010, 89, 171-177. [CrossRef] 
40. Pattiya, A.; Titiloye, J.O.; Bridgwater, A.V. Fast pyrolysis of cassava rhizome in the presence of catalysts. J. Anal. Appl. Pyrolysis 2008, 81, 72-79. [CrossRef]

41. Lu, Q.; Zhang, Z.F.; Dong, C.Q.; Zhu, X.F. Catalytic Upgrading of Biomass Fast Pyrolysis Vapors with Nano Metal Oxides: An Analytical Py-GC/MS Study. Energies 2010, 3, 1805-1820. [CrossRef]

42. Grams, J.; Niewiadomski, M.; Ruppert, A.M.; Kwapiński, W. Influence of Ni catalyst support on the product distribution of cellulose fast pyrolysis vapors upgrading. J. Anal. Appl. Pyrolysis 2015, 113, 557-563. [CrossRef]

43. Dong, C.; Zhang, Z.; Lu, Q.; Yang, Y. Characteristics and mechanism study of analytical fast pyrolysis of poplar wood. Energy Convers. Manag. 2012, 57, 49-59. [CrossRef]

44. Jiang, G.; Nowakowski, D.J.; Bridgwater, A.V. Effect of the temperature on the composition of lignin pyrolysis products. Energy Fuels 2010, 24, 4470-4475. [CrossRef]

45. Hosoya, T.; Kawamoto, H.; Saka, S. Secondary reactions of lignin-derived primary tar components. J. Anal. Appl. Pyrolysis 2008, 83, 78-87. [CrossRef]

46. Melligan, F.; Hayes, M.H.B.; Kwapinski, W.; Leahy, J.J. A study of hydrogen pressure during hydropyrolysis of Miscanthus $x$ giganteus and online catalytic vapour upgrading with Ni on ZSM-5. J. Anal. Appl. Pyrolysis 2013, 103, 369-377. [CrossRef]

47. Şenol, O.İ.; Ryymin, E.-M.; Viljava, T.-R.; Krause, A.O.I. Effect of hydrogen sulphide on the hydrodeoxygenation of aromatic and aliphatic oxygenates on sulphided catalysts. J. Mol. Catal. A Chem. 2007, 277, 107-112. [CrossRef]

48. Bui, V.N.; Laurenti, D.; Afanasiev, P.; Geantet, C. Hydrodeoxygenation of guaiacol with CoMo catalysts. Part I: Promoting effect of cobalt on HDO selectivity and activity. Appl. Catal. B Environ. 2011, 101, 239-245. [CrossRef]

49. Elliott, D.C. Historical developments in hydroprocessing bio-oils. Energy Fuels 2007, 21, 1792-1815. [CrossRef]

50. Ruddy, D.A.; Schaidle, J.A.; Ferrell, J.R., III; Wang, J.; Moens, L.; Hensley, J.S. Recent advances in heterogeneous catalysts for bio-oil upgrading via "ex situ catalytic fast pyrolysis": Catalyst development through the study of model compounds. Green Chem. 2014, 16, 454-490. [CrossRef]

51. Adam, J.A.E.; Lappas, A.; Stocker, M.; Nilsen, M.H.; Bouzga, A. Investigation of the effect of metal sites in $\mathrm{Me}-\mathrm{Al}-\mathrm{MCM}-41(\mathrm{Me}=\mathrm{Fe}, \mathrm{Cu}$ or $\mathrm{Zn}$ ) on the catalytic upgrading of biomass derived fast pyrolysis vapours in a fixed bed reactor using mesoporous materials. Microporous Mesoporous Mater. 2007, 96, 93-101. [CrossRef]

52. Sun, L.; Zhang, X.; Chen, L.; Zhao, B.; Yang, S.; Xie, X. Effects of Fe contents on fast pyrolysis of biomass with Fe/CaO catalysts. J. Anal. Appl. Pyrol. 2016, 119, 133-138. [CrossRef]

53. Karnjanakom, S.; Bayu, A.; Xiaoketi, P.; Hao, X.; Kongparakul, S.; Samart, C.; Abudula, A.; Guan, G. Selective production of aromatic hydrocarbons from catalytic pyrolysis of biomass over $\mathrm{Cu}$ or Fe loaded mesoporous rod-like alumina. RSC Adv. 2016, 6, 50618-50629. [CrossRef]

54. Karagoz, S.; Kawakami, T.; Kako, A.; Iiguni, Y.; Ohtani, H. Single shot pyrolysis and on-line conversion of lignocellulosic biomass with HZSM-5 catalyst using tandem micro-reactor-GC-MS. RSC Adv. 2016, 6, 46108-46115. [CrossRef]

55. Mullen, C.A.; Boateng, A.A. Production of aromatic hydrocarbons via catalytic pyrolysis of biomass over Fe-modified HZSM-5 zeolites. ACS Sustain. Chem. Eng. 2015, 3, 1623-1631. [CrossRef]

56. Stefanidis, S.D.; Karakoulia, S.A.; Kalogiannis, K.G.; Iliopoulou, E.F.; Delimitis, A.; Yiannoulakis, H.; Zampetakis, T.; Lappas, A.A.; Triantafyllidis, K.S. Natural magnesium oxide (MgO) catalysts: A cost-effective sustainable alternative to acid zeolites for the in situ upgrading ofbiomass fast pyrolysis oil. Appl. Catal. B Environ. 2016, 196, 155-173. [CrossRef]

(C) 2019 by the authors. Licensee MDPI, Basel, Switzerland. This article is an open access article distributed under the terms and conditions of the Creative Commons Attribution (CC BY) license (http://creativecommons.org/licenses/by/4.0/). 